R. Fistorta, Sfa Paulo, n. 127-128, p. 37-51, ago-dez/92 a jan-jul/93.

\title{
MEDICINA E TRABALHO: AS "CIÊNCIAS DO COMPORTAMENTO" NA DECADA DE 40
}

\section{Claudio Bertolli Filho *}

RESUMO: A aecessidade de modernizaçato das relaçbes de trabalho oa indtistria brasilein sitwou a vertente "comportamental" da medicina como importante auxiliar no processo de selocko da força de trabalho e na análise "psicologica" dos operários que se mostravam distantes do ordenamento imposto no cotidiano da produçắo. A partir da decada de 40, a psicotecrics, escudada na proposta de "organizaça racional do trabalho" ganhou impulso, assim como a "psicanalise" voltada para as questóes do trabalho. Ambas compuseram postulados "cientificos" explicadores do que era ser "bom" e "mau" trabalhador.

PALAVRAS-CHAVE: História da Medicina, Historia do Trabalho, Psicologia do Trabalho, Medicina e Trabalho, Sabde.

Os anos 20 abriram-se com o empenho do empresariado nacional postar-se como orjentador privilegjado da modernidade brasileira. $O$ afa negador da asserção segundo a qual o país era "essencialmente agricola" colocava em questāo os vínculos entre o capital cafeeiro c a produção industrial, exigindo que a fábrica emblemasse as propostas "regeneradoras" e "progressistas" que deveriam atender aos anseios de uma vasta parcela da população urbana que buscava fugir do rótulo da "barbárie" identificando-se com os modelos preconizados como "civilizados" e, por extensão, "cientffi$\cos ^{n}$.

As inovaçōes redefinidoras do processo de produção e da organização do trabalho que vigiam nas principais nações européias e nos Estados Unidos combinavam-se, no contexto nacional, com a necessidade de expansão da capacidade produtiva, coagindo o empresariado a corrigir a rota traçada pelo projeto industrialista inaugurado nas últimas décadas do século $\mathrm{XIX}$. As unidades fabris, centradas especialmente na cidade de São Paulo, receberam. incentivos para a produção de bens de capital até entáo estranhos ao parque industrial brasileiro, tais como o cimento, o aço maleável e uma variedade de

Doutorando aa área de Historia Social na Universidade de S\&o Panlo e Professor no Instituto de Ciencias Humanas da Universidade do Vale do Parafba e no Departamento de Historia das Faculdades Metropolitanas Unidas. 
FULO, Clandio Bertolli. Medicina e trabolbo: as "ciencias do comportamento" na decads de 40.

máquinas de porte, assim como o "consumidor moderno" cobrava a elaboracão, no país, de ltens já considerados como imprescindíveis para muitos, desde o dentifricio e a lamina de barbear até discos de vitrola, papel fotográfico e baterias de automóveis ${ }^{1}$.

A modernizaçāo dos elos produtivos conjugava-se com a urgéncia atualizadora dos critérios de seleção da força de trabalho e das relaçőes sociais alimentadas no espaço fabril. No "ano modernista" de 1922, o médico Afranio Peixoto alertava para a necessidade de recorrência às novas fórmulas de recrutamento do operariado, ressaltando que a morosidade na realização das tarefas produtivas, os acidentes de trabalho e os conflitos que pontuavam o cotidiano das indústrias deviam-se, em conjunto, à atuação dos "degenerados morais" imprudentemente integrados à linha de produção. Por isto, este higienista recomendava à classe patronal a adoção de "critérios racionais" para a seleção dos trabalhadores das fábricas e das oficinas, definindo o ambiente de trabalho como espaço "em que se viciam todos os meios de vida, facilitam-se todas as ocasiōes de agressão e nocividade naturais, aumentadas ainda agora pela rotina, prejuízo e má educação do proletariado, mal alimentado, mal vestido, mal alojado, viciado pelo álcool e pelo fumo" 2 .

Alguns anos depois, Afranio Peixoto participou da primeira tentativa acadêmica cujo objetivo único era a análise do trabalho sob a ótica médicolegal. Associando-se aos clínicos Flaminio Fávero e Leonídio Ribeiro, o Dr. Peixoto tomou-se co-responsável por um texto onde ficaram estabelecidos os fundamentos jurf́dicos e hipocráticos de análise da mão-de-obra integrada ao processo de produção e também dos acidentados no recinto industrial. Nesta cirurgia, fixou-se as bases nacionais da infortunística, setor de confluéncia de várias especialidades e voltado para o estudo das condiçōes materiais de trabalho e das possibilidades do ambiente das máquinas constituir-se em fator de risco para a saúde dos personagens fabris. Em coerência com que anteriormente havia escrito, Afranio Peixoto reclamava para o médico, mais do que para o advogado, o posto de comando das tarefas de avaliação e disciplinarização do operariado urbano, tecendo referéncias à psicotécnica como área do saber plenamente capacitada para selecionar os operários, "corrigir" os faltosos e, em continuidade, garantir um melhor rendimento do trabalho industrial ${ }^{3}$.

1 WARREN, Dean. "A industrializaçio durante a Reptblica Velha" In: Fausto, Boris (org.) - Hiscória Genal da Civilizoçōo Brasileira Sło Puulo: Difel, 1975, Vol. 8, p.264-265.

2 AFRANIO, Peixota. Higiene. $3^{\circ} \mathrm{ed}$, Rio de Janeiro:Francisco Aves, 1920, Vol. 1, p360.

3 PEIXOTO, A, FAVERO, F. e RIBEIRO, L - Medicina Legal dos Acidentes de Trabalho e des Doencess Profissionaes. Rio de Janeiro; Frapcisco Alves, 1926. 
R. Historta, Sfo Paulo, a. 127.128, p. 37.51, ago-dez/92 a jan-jul/93.

"The right man in the right place" passou a ser o lema que, importado dos Estados Unidos, tornou-se a meta perseguida pela classe patronal brasileira. A seleção e ajustamento do trabalhador ao ordenamento fabril incentivou que os nomes de Frederick Taylor, Henry Ford e Henry Fayol tornassem-se menções obrigatórias nos pronunciamentos dos "capitáes" da indústria nacional, exponenciando a necessidade de revisão criteriosa đos princípios organizadores do trabalho, inclusive sob o ponto de vista da psicologia.

Por isto, ainda nos anos 20 , o empresariado patrocinou a vinda ao Brasil de Henri Piéron e Léon Walther - professores, respectivamente, da Sorbonne e da Universidade de Genebra - para que estes especialistas ministrassem cursos pioneiros no ensino dos conceitos básicos da psicotécnica, área apresentada como síntese das "ciências do comportamenton aplicada à realidade industrial ${ }^{4}$. Paralelamente, a classe patronal buscava compor-se em entidades representativas, resultando na fundação, em junho de 1928, do Centro das Indústrias do Estado de São Paulo (CIESP) e, tres anos mais tarde, no inf́cio das atividades do Instituto de Organização Racional do Trabalho (IDORT).

Os estudos desenvolvidos por estas associações - que contavam com a assessoria da Escola Livre de Sociologia e Política de São Paulo, criada no ano seguinte à chamada "Revolução Constitucionalista" -, viabilizaram a multiplicação das perspectivas de entendimento do proletariado urbano. A enfase conferida à análise do comportamento individual c coletivo dos agrupamentos operários incentivou que diferentes pesquisadores convergissem para enfoques psicológicos dos trabalhadores, resultando no fato que especialmente os médicos, mas também os pedagogos, os advogados e os cientistas sociais reclamassem para si o título de psicólogos, se nảo de psiquiatras e psicanalistas. Processo marcado pela lentidäo nos anos 30, na década seguinte ganhou projeção a "medicina do comportamento" que, incluindo a psicotécnica, firmou-se como dispositivo abalizado para a dissecaçăo e julgamento da rotina e das disfunções que caracterizavam o cotidiano industrial.

4 WALTHER, Dr Loon. Techro-Psychologia do Trabalho Indhertial Slo Paula, Comp Melborementos de S. Paulo, 1929, p88. Acrescenta-se que este livro fol trutucido pare o partugute e prefeciado por Manuel Bergström Lourenco Filho, professor que poucos anco depols alcangon projeça nacional como um dos mentores do movimento escolinovieth. 
FILHO, Clandio Bertalli. Medicina e trabalho: as "ciencias do comportamento" na decada de 40.

\section{A SELEÇĀO E ACOMPANHAMENTO DOS TRABALHADORES}

Fruto da orientação adotada tanto pelo IDORT quanto por outras instituições congeneres criadas no decorrer dos anos 30 nas principais cidades do pals, definiu-se a lógica da "organização racional" das tarefas fabris e do perfil ideal dos agentes sociais diretamente ligados à produção, demarcando o campo de envolvimento da "psicologia do trabalho".

Neste contexto, o clínico Raul Rocha, funcionário do Departamento de Assistencia Médico-Social da Secretaria de Saúde do Rio de Janeiro, revelou-se como um dos principais apólogos dos recursos oferecidos pela psicotécnica. No mais conhecido de seus livros, prefaciado pelo psiquiatra Henrique Roxo, a medicina voltada para as questöes industriais buscava afinar-se com os interesses do governo de Getúlio Vargas, declarando seus objetivos: "dar completa eficiencia ao trabalho e, ao mesmo tempo, poupar e preservar o trabalhador" e com is to "economizar material, trabalho e dinheirons.

Fiel a estes compromissos, o clínico mesclou princípios emprestados da psicologia e da ergonomia, da sociologia e da economia para ensinar que - "fator anatomo-fisiologico" individual - também denominado "substrato organico" - não poderia ser alterado pela medicina que, em compensação, contava com um arsenal de conhecimentos solidos e eficientes para corrigir a "ação mental" do agrupamento operário.

Neste contexto cabe a pergunta: para os "psicologistas", qual era o tipo ideal de trabalhador? Segundo as instruções do Dr. Rocha, o operário modelo era aquele que, tanto em condiçōes propícias quanto adversas (como por exemplo, em ambientes marcados por calor ou ruído em escala excessiva) cstava capacitado para atuar satisfatoriamente no processo produtivo, sentença que incluia o bom rendimento do trabalho e a irrestrita obediencia às ordens emanadas pela chefia da empresa. Em contraposiçāo, o servidor "inadaptado" era aquele que, por "fatores intelectuais, morais e afetivos" pervertia o recinto de labuta grupal, mostrando-se negligente, despreocupado, preguiçoso e por isto insuflador do descontentamento coletivo e causador de acidentes comprometedores do bom funcionamento da fábrica.

Tais constatações coagiram o Dr. Rocha a reiterar a necessidade de novas formas de relacionamento entre os empregados e seus superiores

5 ROCHA, Ranl. Assistencia Psychovechrica Estudo Techrico do Homem no Trabalho. Sfo Pavlo, Bditore Nactonal, 1940, p.9. 
hierárquicos, formas estas que, para a garantia da lucratividade dos negócios, precisariam ser pautadas pelos recursos oferecidos pela psicotécnica. Elaboradora do modelo perfeito do "bom trabalhador", as "ciencias do comportamento" ampliavam suas perspectivas, anunciando também o paradigma do "patrão moderno". Como tal, entendia-se o administrador de empresa que acompanhava scus empregados praticamente desde o nascimento, para isto criando escolas onde, desde os primeiros anos de vida, a força de trabalho em estado potencial deveria ser disciplinada e orientada vocacionalmente sendo que, no decorrer deste processo, seriam dispensados todos os aprendizes que se mostrassem avessos à faina cotidiana, à submissão às ordens, à vida em conjunto e à demonstração de solidariedade em relação ao grupo patronal ${ }^{6}$.

Se os industriais haviam por um longo perfodo negligenciado a educação continuada do agrupamento proletário, a medida alternativa imediata consistia na aplicação de rígidos testes para a admissão dos operários que batiam à porta das fábricas em busca de colocação. $O$ primeiro passo na seleção dos trabalhadores, segundo os critérios proporcionados pela psicotécnica, referia-se ao levantamento dos dados individuais, seguindo um roteiro que alinhavava uma série inusitada de questões, cujas respostas deveriam ser registradas em fichas apropriadas, por um "psicologo" devidamente treinado na "triagem científica" da força de trabalho. Essas fichas, se preenchidas integralmente, revelavam-se uma minuciosa fonte de informaçōes sobre 0 operário, sua famflia e seus amigos, incluindo af a idade de seus pais ao casarem e as "tendencias psicológicas" dos progenitores do trabalhador. Prosseguindo nas averigüaçōes, exigia-se ainda do candidato uma detalhada descrição de sua vida, desde as suas mais antigas lembranças ate o momento da entrevista, perfazendo assim uma história de vida que, analisada, resultaria ou não na incorporação do ọperário.

A "medicina do comportamento industrial" multiplicava suas estrategias de conhecimento do proletariado. No final da década de 40, o médico Arlindo Ramos foi apresentado pelo polf́tico e empresário Roberto Simonsen e também pelo psiquiatra espanhol Emilio Mira Y Lopez como o mais atuante psicotécnico brasileiro, inclusive porque havia conferido maior "ẻlasticidade e abrangencia" ao "exame de temperamento e personalidade" dos servidores fabris. Proclamando-se discípulo de Taylor, o Dr. Ramos assumiu como tese dominante no seu principal estudo o princípio de que, mesmo para os "cargos de responsabilidade", o importante não era tanto a aplicaçáo de "testes de

Idem, p.151. 
FIL HO, Candio Bertolli. Medicina e trabalbo: as "ciencias do comportamento" na decada de 40.

inteligencia", mas sim de exames que poderiam assinalar a existencia de distúrbios pré-psicóticos, facilitando a operação de alijamento dos "doentes" do mundo da produção?

Para realizar o "exame de temperamento e personalidade", o médico enfatizou a necessidade de recorrencia à uma série de dispositivos que certamente causavam assombro à măo-de-obra avaliada. Inicialmente o candidato era instado a se submeter ao psicodiagnóstico segundo os protocolos de Rorschach para, em seguida, responder "sim" ou "não" às 116 perguntas componentes do inventário de Woodworth-Mathews que, adaptado para o contexto brasileiro, compreendia questões como as seguintes: "Voce é mais medroso que os outros?"; "Voce as vezes sonha com mortos?"; "Voce pode ficar sentado muito tempo sem se mexer?"; "Voce resiste à dor tanto quanto os outros?"; "Voce acredita em azar?"; "Voce já sentiu desejo de provocar um incendio"?; "Voce gosta de caçar?" e "Voce já teve vontade de roubar?"8.

Os testes de seleção deveriam ser, mais exigentes ainda quando os candidatos almejavam colocação junto às casas bancárias ou lojas comerciais onde, por 6bvio, havia maiores possibilidades de ocorrer furtos. Nestes casos, - Dr. Ramos indicava a utilizaçăo paralela de um aparelho denominado "Polígrafo de Keller", dispositivo empregado desde a década de 20 pela polfcia norte-americana e por isto conhecido como "revelador de mentiras". Este mecanismo permitia o registro da pressão arterial, da respiração e do reflexo psico-galvânico do entrevistado, em situações tensas propositadamente suscitadas durante o exame. Graças a esta estratégia, a medicina acreditava poder descobrir as "perturbações emotivas" freqüentes nos portadores de "personalidades psicopatas", excluindo da lista de eventuais contratados os indivfduos cujas respostas ou reações corporais sugerissem "anormalidade mental".

Em continuidade, o mesmo médico cobrava dos gerentes industriais a extensáo das atividades psicotécnicas para todo o ambiente fabril, com o objetivo de acompanhar a integraçảỏ dos funcionários no processo de produçăo de mercadorias e na prestação de serviços. Acreditando que o trabalhador "sempre pode produzir mais do que realmente faz", a clínica propunha o "julgamento contínuo" do operariado, buscando estabelecer formas corretivas dos empregados "desajustados", grupo classificado aprioristicamente

7 RAMOS, Artindo. Pricologia Aplicada no Trabalho. Rio de Janeiro: Companbia Brasileira de Artes Orificas, s.d (c. 1948).

8 Idem, P258-260. 
R. Histortn, Sto Paulo, n. 127-128, p. 37-51, ago-dez/92 a jan-jul/93.

como composto de "neuróticos que fracassaram socialmente" "e que, por isto, mostravam-se perigosos para a comunidade laboriosa. Caso nada fosse conseguido mediante o emprego da "higiene mental", restaria uma única safda: a dispensa do funcionário "mentalmente perturbado".

As propostas emanadas em nome da psicotécnica, entretanto destoavam dos interesses imediatos da classe patronal brasileira. Certamente foram poucas as empresas que se dispuseram a arcar com os custos représentados pela multiplicidade e pela abrangência das orientações prescritas pelos "psi-

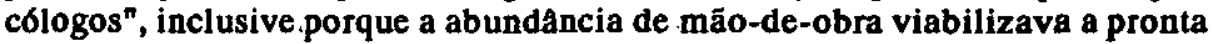
substituição dos funcionários "inadaptados". Até mesmo a burocracia estatàl, representada a partir de 1938 pelo Departamento Administrativo de Serviço Público (DASP), mostrou-se pouco disposta a acatar critérios rígidos de seleçáo dos servidores públicos, impondo apenas o exame abalizado dos "aparelhos fisiologicos" e principalmente do aparelho visual, concedendo pouca atençāo aos dados de ordem psicológica dos candidatos, dispensandoos de interrogatorios mais prolongados 9 .

De qualquer forma, a sugestão de estudo e acompanhamento "cientifi$c^{n}$ dos trabalhadores ganhou resposta do émpresariado nacional, frutificando ainda na década de $40 \mathrm{em}$ entidades como o SENAI, o SENAC e o SESI. Uma nova vaga modernizadora das relações de trabalho levoü estes serviços a desenvolverem atividades no campo da psicologia e especialmente da psicotécnicá, reproduzinđo a linha de atuação dos industriais nofte-americanos, os quais patrocinavam as atividades de 6rgãos como o National Institute of Industrial Psychology e o Tavistock Institute of Human Relations. Assim, no ano de 1946 o SESI inaugurou um setor de orientação psicotécnica, seguido pouco tempo depois pelo SENAC, que convidou o professor LCon Walther a retornar ao Brasil e aqui desempenhar a funçáo de diretor das pesquisas motivadas pelo "comportamento operário" ${ }_{i}$.

A constituição de novos pólos de análise voltados para a "psicologia do trabalho" permitiu que vozes diferenciadas se mesclassem, ditando rumo

9 As etapas dos exames médicos dos candidatos aos cargos e funçbes publicas alto descritas em: Gonzaga, A Gavilo - "Exames prtvios de sanidade e capacidade fisica" Anquivas de Higieno 17(1):137-164, Março de 1947.

10 A importaçáo do modelo norte-americano na criaçato dos escritorios de paicologla industrial no

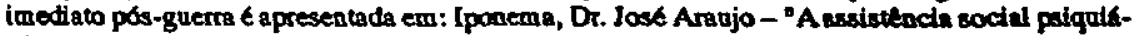
trica na industria" A Folha Medeca 31(9):66-68, Maio de 1950 e Continho, Dr. Morats - "As relagetes industriais nos Estados Unidos" Jornal Brasileino de Psiguiatria 1(7):101-105, Julho de 1950. 
FILHO, Clandio Bertolli. Medicima e trabalho: as "clencias do comportamento" na décenta de 40.

tortuoso aos debates centrados nas questóes acerca da seleção profissional e da saúde mental do operariado. "Humanizar o trabalho" passou a ser o lema permeador das apologias de umaiparcela consideravel dos clínicos voltados para a problemática da produçăo, incentivando as interpretaçőes multifatoriais sobre os desarranjos que perturbavam a rotina das fábricas.

O Dr. Flaminio Fávero - docente da Faculdade de Medicina da Universidade de, Săo Paulo e também líder presbiteriano fundamentalista - fazia questăo de declarar sua fé, utilizando o termo "solidariedade" como referencial básico para advogar o fim dos conflitos entre operários e patrōes. Como paliativo dos contrastes de interesses entre o capital e o trabalho, 0 Dr. Fávero cobrava o respeito empresarial à legislaçăo trabalhista e principalmente a ampliação das atividades assistenciais financiadas pelos proprietários das fábricas, estabelecendo o objetivo destes serviços como "todo conjunto de obras feitas ou auspiciadas pela indústria, destinadas a elevar o nivel de dedicados obreiros e empregados, e que têm uma influéncia indireta sobre a capacidade produtivan. Na seqüéncia, o mesmo clínico postava-se contra os operários que criticavam o grupo patronal, alertando que as medidas assistencialistas e promotoras do bem-estar do proletariado revelavam-se provas flagrantes do despojo e das boas intenções do grupo dirigente. Assim, em vez de revolta, o professor Fávero cobrava dos trabalhadores humildes agradecimentos pelos privilégios que vinham recebendo de seus empregadores, ressaltando que as novas iniciativas fomentadas pela elite industrial não eram indispensáveis para o bom funcionamento das unidades fabris e que tambem năo se constituíam em obrigaçăo imposta por lei ${ }^{11}$.

A percepção médica das atividades produtivas como fruto do relacionamento harmonioso entre operários e industriais e os serviços sociais como dadiva dos "gerentes modernos" combinava-se com o apregoamento da necessidade de seleçáo criteriosa dos empregados, medida inibidora da presença dos "inadaptados" que, ao rejeitarem o direcionamento imposto pela estrutura fabril, revelavam-se indivíduos "perigosos". Tão perigosos quanto os funcionários que insistiam em cobrar indenizaçōes indevidas após serem acidentados no trabalho.

11 FAVERO, Prof. Flaminio. "A medicina e a humanizaço do trabalbo" Neuntrio 7(2):10, 20 Trimextre de 1947. Enquanto lfder de uma vertente mbdica, o Dr. Fávero teve suas idclas emprestadas por vartos outros clínicos, inclusive por: Montenegra, Francisco - "Sadide e produça" Jomal de Medicina de Permambuco 45 (5):89-104, Maio-Junho de 1949 e Gujmartes, Dr. Adriano Taunay Leite - "A medicina social psiquiatrica como fator de higjene e segurança do trabalbo" A Folha Médica 31(5):35-36, Março de 1950. 
R. Htst6rta, S5o Paulo, n. 127-128, p. 37-51, ago-dez/92 a jan-jul/93.

\section{AS VITTIMAS DA SINISTROSE}

Um segundo campo de intervençăo das "ciências do comportamento" nas questões originadas pela produção dava-se através da análise dos operários que apresentavam possiveis "transtornos mentais", causadores ou resultantes de acidentes que comprometiam a existencia do indivíduo e dos seus companheiros de labuta. Nestas circunstancias, principalmente após a instituição da Justiça do Trabalho, no ano de 1939, os "psicólogos" e "psiquiatras" passaram a ser recrutados para atuarem como peritos em processos judiciais justificados pelos pedidos de indenizaçōes movidos pelos operários acidentados. Com isto, os especialistas em "comportamento industrial" tenderam a se voltar para a psicanálise, anunciando esta área enquanto "ramo da psicologia criado por Sigmund Freud" e formado por um saber tão "prático" e eficiente quanto os demais setores da profissão médica ${ }^{12}$.

O campo epistemológico da psicanálise, entretanto, apresentava-se frágil e lacunar frente às exigências jurídicas. A ausência de um "quadro nosologico" amplo e "comprovado" segundo as exigencias da logica positivista, levava os advogados - e mesmo uma ampla parcela da comunidade médica - a suspeitarem da validade dos laudos preparados pelos discípulos de Freud. Em continuidade, tornou-se regra os "psicanalistas" recorrerem à orientação da escola liderada pelo médico, polf́tico e industrial paulista Antonio Carlos Pacheco e Silva, que apresentava a maior parte das "patologias mentais" como resultado de disfunçōes glandulares ou de traumatismo físico. Contando com um referencial concreto - o agravo corporal ocorrido durante as horas de trabalho - os peritos em "psicologia industrial" sentiamse mais seguros para declarar ou não o operário como merecedor de indenização e de aposentadoria, temporária ou permanente ${ }^{13}$.

A inclinação dos facultativos postarem-se contra os acidentados que reclamavam judicialmente reparação económica ensejou que o fenomeno

12 MARCONDES, Durval. "Aspectos do aproveitamento prático da Psicanálise" Newobiologia 2(1):1, Março de 1939. O movimento médico pela incorporaçăo desta especialidade wa rotina clfnica foi historiado em: Mokrejs, Elisabete - A Psicandálise no Bravil. Petrópolis: Vozes, 1993.

13 Seguindo esta tendencia, veja-se: Ribeiro, Dr. Gabriel Duarte - "Conceito de alienactio mental e de peralisia na interpretaçáo dos arts. 208 e 215 do Codigo de Vencimentos e Vuntagens dos Mi. litares do Exercito", Revista de Medicina Militor 39(4):531-536, Outubro-Dezembro de 1940. Um dos principais livros onde o médico AC. Pacheco e Silva expoe suas idéias sobre as passtveis relagóes entre acidentes de trabalho e desordens mentais tem como referencia: - Psiguiatria Clinica e Forense. Sfao Paula: Editora Nacional, 1940, especialmente p.400-460. 
FllAO, Crudio Bertili. Medicina e trabalbo: as "cikacias do comportamento" na decada de 40.

fosse analisado detalhadamente pela comunidade especializada. Convocados para tocerem laudos sobre funcionários que pediam recompensa por danos à saúde, os médicos convergiam para o diagnóstico da existencia de traumatismos físicos favorecedores do desenvolvimento de "neuroses de responsabilização" dos patróes pelo acidente de trabalho, sentimento rotulado pela medicina como "sinistrose", "neurose de renda", "neurose de desejo" e "indenizofilia". Apesar da pluralidade de denominacooes, a "patologia" que acometia os trabalhadores acidentados contava com definiçáo única: "um delírio pleitista, querelante, de reivindicação"14.

A constancia de processos legais que requeriam o parecer dos psicanalistas motivou as publicaçóes corporativas a abrirem espaços para a análise do comportamento tido como característico entre os operários acometidos pela moléstia da sinistrose. A semelhança entre as avaliações assinadas pelos peritos e significativa: todos os operários pesquisados foram anunciados como "bons trabalhadores" e "responsáveis pais de famf́lia". Ocorrido o acidente durante o trabalho, os pacientes permaneceram por algum tempo sob tratamento médico, declarando unissonamente não desejarem qualquer tipo de indenizaçăo. Tidos como plenamente recuperados para reincetar suas atividades profissionais, segundo os psicanalistas, parece que estes operários "perdiam o amor pelo trabalho", dizendo-se incapacitados para retornar, de imediato, para o espaço das máquinas. Nesta situação, os doentes passavam a percorrer inúmeros centros hospitalares e clínicas particulares, à procura da recuperaçăo física ao mesmo tempo que, ainda segundo a trajetória traçada pelos médicos, insuflados pelos "maus conselhos" dos colegas de profissão, os querelantes empenhavam-se aguerridamente em obter a indenização pelo agravo à saúde. A incapacidade da clínica geral certificar a veracidade das queixas apresentadas pelos pacientes abria oportunidade para os "psicanalistas" intervirem na questão, atuando como peritos responsáveis pela solução do impasse médico-legal, através do estabelecimento dos possíveis nexos causais entre o infortúnio e a afecção nervosa ou mental que reduzia ou anulava por completo a capacidade produtiva do trabalhador ${ }^{15}$.

14 PACHECO e SIIVA, AC. "Acidentes do trabalho e desordens mentais" In: - Palasras de Psiqriotra Sto Pavla, ac.p, 1950, p313. Este artigo foi publicado originalmente no ano de 1947. Cabe resaltar que o termo sinistrose foi incorporado no vocsbulário mético e jurfícico a partir de 1926, atravts do livro composto pelos Drs. Afranio Peixoto, Flaminio Fávero e Leonídio Ribeira, mencionendo em nota anterior.

15 O podrio das casos oode se necessitava a participaglo da "medicina do comportamento" enconim-se em: Almeida Prada, Dr. J.N. - "Dn eletroplessffo psiobgena" Anquivas de Assistência nas Psicopacas do Extado de So Panlo 6(1-2):189-213, Marco-Junbo de 1941 e também em: Garcia, J.Alves - "O exidente de trabalho em psico-patologia" Revista do Centro de Psiquiatria Nacio. nal 2(3-1):72-81, ano de 1947. 
R. Htst6ris, SAo Paulo, n. 127-128, p. 37-51, ago-dez/92 a jan-jul/93.

A tendéncia predominante entre os estudiosos dos segredos do "comportamento industrial" era declarar o reclamante como um "simulador" que buscava extorquir as companhias seguradoras e, em continuidade, negar 0 pedido de indenização ou, pelo menos, anunciar a falta de evidencias para tomar qualquer tipo de decisão de caráter legal. Foi is to que ocorreu com o estivador J.R.S., que viu seu pedido de ressarcimento por traumatismo físico ser protelado pelo Dr. Edístio Pondé. O paciente, um homem negro de 39 anos de idade, sofreu uma queda enquanto trabalhava no interior de um navio carvoeiro, fato que causou-1he múltiplas fraturas, inclusive no maxilar e também nos membros superiores e inferiores. Internado no Hospital da Faculdade de Medicina da Bahia por um periodo não definido na documentação clínica, o estivador foi declarado apto para voltar ao trabalho algum tempo depois do sinistro, decisão que não foi aceita por J.R.S. que dizia sofrer de fortes dores nas regiōes atingidas pela queda, tonturas constantes e ainda de perda parcial da audição. Examinado por vários médicos e também pelo Dr. Pondé, o estivador foi qualificado como mentor de um engodo contra seus patrões, já que nenhum dos clínicos encarregados do caso conseguiu encontrar "explicações científicas" para as constantes queixas apresentadas pelo paciente ${ }^{16}$.

Na série de casos que obtiveram destaque na imprensa especializada ganha sentido de exceção a disputa judicial que contou com a participação do médico e escritor Dyonelio Machado, funcionário da Santa Casa da capital do Rio Grande do Sul. Convocado para tecer um laudo sobre um operário acidentado, o clínico registrou os seguintes dados: N.S., com 39 anos de idade e natural da Polónia, ganhava a vida como motorneiro cm Porto Alegre quando, em novembro de 1941 , ao acionar uma alavanca do bonde que dirigia, recebeu uma "violenta" descarga elétrica que o deixou desacordado por cerca de dez minutos. Após este intervalo, o servidor da companhia de transportes recobrou "plenamente" os sentidos, conduzindo o veŕculo até a estação terminal. Na manhã do dia seguinte, N.S. foi tomado por vomitos e intensa cefaléia, sendo imediatamente internado em um hospital, onde permaneceu por quase dois meses. Tendo recebido alta nosocomial como "curado", o motorneiro insurgiu-se contra a decisão clínica, alegando que padecia de "dores de cabeça, tontura e insonia", acrescentando pouco depois informaçöes interpretadas pelo médico como sendo sinais de "inibiçăo psicomotora, 
FILHO, Clavdio Bertolli. Medicioa e trabalho: as "ciencias do comportamento" na diceada de 40.

idéias hipocondriacas, fatigabilidade, irritabilidade e expressáo fisionもmica de tristezan"17.

A negativa do operário retornar ao emprego e a reiteração do pedido de indenizaçăo levaram o Dr. Machado supor, em um primeiro momento, que - polones fora vitimado por uma "neurose traumática" ortginada pelo choque clétrico ocorrido meses antes. No decorrer da série de exames periciais exigidos pela justiça, parece que o especialista gaúcho foi tocado pela indecisăo sobre o verdadeiro estado de saúde do paciente queixoso, concluindo seu relatorio de forma desconcertante: a formação industrial, os acidentes de trabalho, a "neurose de litigio" e a legislação trabalhista constitúam-se, para o autor do laudo, em facetas do mundo moderno, umas sobredeterminando as outras, e resultando numa "realidade" complexa e indecifrável para a clínica. Doente ou simulador? Era a questão que continuava a pairar sobre a figura do motomeiro. Na dúvida, o Dr. Dyonelio achou uma solução paliativa: se o paciente estivesse mentindo deliberadamente, mesmo assim ele estaria dando provas de seu estado enfermo, pois a mentira também poderia ser classificada enquanto patologia. Afirmando que a "sinistrose so se cura com a indenização", o perito năo titubeou mais, reclamando "justa reparação" ao trabalhador acidentado.

Produto acabado do enfoque clínico que desmerecia as queixas dos operários e đa "psicologização" desenfreada dos acidentados no trabalho é a perícia realizada pelo médico Cicero de Sousa, professor da Universidade de São Paulo, tendo como objeto o serralheiro M.M., de 24 anos de idade e que, no espaço de um ano, fora por dezessete vezes vitimado por sinistros de pequena e média proporçōes, tais como perda de unhas, marteladas desferidas contra o próprio corpo e queimaduras ${ }^{18}$.

Instado a esclarecer os motivos da seqüencia de acidentes que faziam - operário recorrer mensalmente à companhia seguradora a qual era associado, o Dr. Cicero buscou conhecer a trajetória de vida e a "complexidade psicologica" de M.M., submetendo-o à uma série de entrevistas e testes, inclusive o psicodiagnóstico de Rorschach. Como resultado, o perito certificou-se dos principais traços da personalidade do multiacidentado: "recalque da afetividade e da imaginação", "espírito seco, rigido, sem mobilidade,

17 MACHADO, Dyonelia "Neurose traumática" Arquivas do Departamento de Saride do Rio Grande do Sul 4: 57, ano de 1943.

18 SOUSA, Cicero Christiano de. "Acidentes múltiplos como sintoma neurbdion" Anquivas de NeuMa-Priguiatia S(2):155-166, Junho de 1947. 
R. Historta, Sto Paulo, n. 127-128, p. 37-51, ago-dez/92 a jan-jol/93.

estereotipado em seus pequenos interesses", "ansiedade", "logica não muito rigorosa" e ainda irritabilidade, fobias, dúvidas e sentimento de inveja.

Munido destes dados, o clínico buscou outras informaçōes contextualizadoras da trajetoria íntima do operário, indagando-o sobre sua experiencia familiar e seu ćrculo de amigos. Em resposta, o professor Cicero de Sousa soube que o paciente fazia parte de uma família de trabalhadores, contando além do depoente, com seus progenitores, uma irmã 13 anos mais velha que - "doente" e um irmăo 3 anos mais jovem, havendo o esclarecimento de que todos os homens do clā exerciam a mesma profissão. Além disto, o perito foi alertado que o maior desejo do paciente era "ver os pais felizes" e que desde janeiro de 1945 ele havia se afastado de seus amigos, pois neste mes havia contrafdo núpcias.

A partir destes dados, que não foram detalhados em sua exposição academica, o Dr. Cicero montou uma estrutura explicadora para a ocorrencia do conjunto de acidentes que periodicamente afastavam o serralheiro da linha de produção. Primeiramente, o fato de ter nascido mais de uma decada após a irmã fez com que o pesquisador concluisse que tanto o trabalhador como o seu irmão eram "filhos não desejados" pelos pais, condição geradora de sentimentos ambigüos, inclusive de 6 dio inconsciente pela figura materna. As características da composição familiar fizeram o médico suspeitar que M.M. tinha sido uma "criança mimada, superprotegida", fazendo aflorar năo só o "Complexo de Édipo" como também o "Complexo de Caim", já que o irmão estaria ocupando a posição de adversário frente ao amor dos progenitores, estendendo a concorrencia para o campo profissional.

O ódio endereçado à mãe e a rivalidade nutrida em relação ao irmão teriam levado o multiacidentado a buscar formas de punição de seus desejos inconscientes através da mutilaçāo, já que a perda de pequenas partes do corpo, durante os sinistros, foi interpretada como indícios perfeitos de "castração simbólica". Mais ainda, o analista localizou na disputa entre os irmăos serralheiros mais um foco estimulador dos acidentes de trabalho, asseverando que as agressóes auto-provocadas por M.M. constitúam-se em estratégias para atrair a atenção dos pais e assim se postar acima do rival na preferencia e nos cuidados familiares.

O Dr. Cicero mostrava-se insaciável na busca dos elos esclarecedores da vida do trabalhador. O casamento do paciente tamberm ganhou foro de objeto de investigação. Sem levar em conta a possibilidade de licença do serviço para desfrutar a lua de mel - benefício já incorporado na legislação trabalhista então vigente - o médico informou que, durante o mes em que foi celebrado o matrimónio, o operário foi vitimado por apenas um único acidente, explicando a coincidéncia pelo fato da cerimónia ter chamado a atenção 
FLHO, Cantio Bertolli. Medicina e trabalho: as "ciencias do comportamen to" na decada de 40.

familiar, nמ̃o sendo por isto necessário ferir-se para atrair o interesse dos parentes e dos amigos. Mais do que isto, outra relaçăo foi vislumbrada entre - casamento e a suspensão temporária da série de sinistros:

"Deflorando a mulher, (o funcionário) realizou um ato sangrento contra outra pessoa; assim, dirigindo para o exterior a sua agressividade, não teve necessidade de voltá-la contra si. Pelo defloramento, estava simbolicamente castrando outra pessoa e, assim, não tinha necessidade de se mutilar ${ }^{\text {n9 }}$.

O professor-da Universidade de São Paulo ousou realizar ainda uma áltima análise sobre a "personalidade neurótica" do operário seguidamente ferido no trabalho. Segundo o especialista, o relacionamento deturpado com a má, levou o paciente a substituir a figura da progenitora pela companhia seguradora, cobrando da empresa o aconchego e o carinho materno que supostamente o paciente não recebeu durante a infancia. Por isto, pontificou - clínico, o serralheiro se mortificava para receber amparo e mimos, simbolizados nesta situação pelo pagamento do salário pelos dias que, incapacitado, deixou de comparecer ao emprego.

O Dr. Cicero de Sousa, na função de perito da instituição seguradora responsável pelo poliacidentado, construiu um complexo e por vezes contraditório sistema de articulações, unindo os fios da vida do paciente. No final de suas observações, aflorava a condição "anormal" da personalidade do trabalhador como elemento exçlusivo de explicaçāo dos acidentes em série. Buscando fugir à orientação que situava os "comportamentos inadaptados" como produtos de "traumas orgânicos", o médico isolou-se na análise psicologica, decisão que não o impediu de incorrer na elaboração de um diagnóstico exageradamente idealizado. Isto porque, como o próprio clínico registrou em suas anotaçóes, M.M. era totalmente cego do olho direito e contava com capacidade visual muito restrita no outro olho, sendo provável que a deficiencia física, bem mais do que as "neuroses", tenha sido responsável pelos sinistros que de tempo em tempo atingiam o corpo do serralheiro. Se isto for verdade, M.M., como tantos outros trabalhadores, escondia sua condiçăo de quase-cego para manter-se na linha de produção e assim fazer jus a um salário que, mesmo mingüado, assegurava sua sobrevivência e a de sua esposa.

Idem, p.164. 
R. Htstórta, S\&o Paulo, n. 127-128, p. 37-51, ago-dez/92 a jan-jul/93.

No final da década de 40 , as "ciencias do comportamento" firmavam presença nos debates acerca da organização e gerenciamento do trabalho. Momento de redefinição da economia e da política nacional, as atividades produtivas recebiam novas tinturas de modernidade, reiterando o papel da medicina e de seus desdobramentos enquanto dispositivos atualizadores da força de trabalho e do código de vivencia nas fábricas e na área de prestaçáo de serviços. A soma do projeto psicotécnico com a avaliaçăo "psicológica" do operariado, especialmente da parcela dos acidentados, abre oportunidade para a verificaçăo de alguns mecanismos de controlẹ do trabalhador brasileiro, os quais tendiam a imputar o afloramento das contradiçōes permeadoras do cotidiano e do espaço de labuta aos operários vitimados pelos comportamentos "desajustados", negando a importancia dos movimentos de desagrado enquanto canais de relacionamento entre o capital e o trabalho.

Os pronunciamentos médicos, entretanto, não podem ser entendidos apenas enquanto reflexos dos interesses apadrinhados pelas elites patronais. E certo que a intervençăo clínica situava os facultativos tanto como promotores da produçáo quanto como legalizadores dos posicionamentos que imputavam a responsabilidade pelos acidentes de trabalho $c$ as enfermidades profissionais ao próprio proletariado. Ao mesmo tempo, porém, é necessário perceber que a Academia hipocrática buscava estabelecer estratégias "cientificas" de percepção dos eventos individuais e coletivos que, centrados no corpo, incentivavam a modernização da trama coletiva.

Entre o conjuntural expresso pelo momento brasileiro e o estrutural marcado pelo processo de industrialização segundo o código do capitalismo, ganhavam peso os pronunciamentos que, vistoriados pelo historiador, permitem a abertura de novas perspectivas de entendimento sobre o pretérito da "psiquiatria industrial" e também sobre os projetos que visavam a ampla subordinação da força de trabalho às necessidades e ao ritmo intenso da produção fabril.

ABSTRACT: The necessity of modernizing the labor relations in Bradlinn industry made the "behavioral" medicine an important tool in the process of selection of the lebor force in the "pryctological" analysis of the workers which showed to be distant from the discipline impoesd in deily production. From the 1940s, psychotechnology integrated with the concept of "raticanl laber organtzition". gained monentum as well as the "prychoanalysis" geared to labor matters. Both componed "acientific" postulates which explained what was the "good" and "bad" worter.

KEY-WORDS: History of Medicine, History of Labor, Prycholony of Labor, Modictine and Labor, Health. 